\title{
The rs 1892818 polymorphism of ADRB3 is associated with coronary artery disease in a Han population
}

\section{Jin-Yu Zhang}

Department of Rehabilitation,The First Affiliated Hospital of Xinjiang Medical University

\section{Qian Zhao}

Xinjiang Key Laboratory of Cardiovascular Disease Research,Clinical Medical Research Institute of First Affiliated Hospital of Xinjiang Medicai University

\section{Xiao-Mei Li}

Department of Cardiology, the First Affiliated Hospital of Xinjiang Medical University

\section{Fen Liu}

Xinjiang Key Laboratory of Cardiovascular Disease Research,Clinical Medical Research Institute of First Affiliated Hospital of Xinjiang Medical University

\section{Qiang Zhao}

Xinjiang Key Laboratory of Cardiovascular Disease Research, Clinical Medical Research Institute of First Affiliated Hospital of Xinjiang Medical University

\section{Li Men}

Xinjiang Medical University Affiliated First Hospital

\section{Qing-Jie Chen}

Xinjiang Medical University Affiliated First Hospital

\section{Hui Zhai}

Xinjiang Medical University Affiliated First Hospital

\section{Jun-Yi Luo}

Xinjiang Medical University Affiliated First Hospital

\section{Yining Yang (D Yangyn5126@163.com)}

Department of Cardiology,First Affiliated Hospital of Xinjiang Medical University https://orcid.org/0000-0002-83328508

\section{Research}

Keywords: $\beta 3$-adrenergic receptor, coronary artery disease, gene, single nucleotide polymorphism

Posted Date: January 17th, 2020

DOI: https://doi.org/10.21203/rs.2.21202/v1

License: (c) This work is licensed under a Creative Commons Attribution 4.0 International License. Read Full License 


\section{Abstract}

Background: Coronary artery disease (CAD) is the most common type of heart disease and causes high morbidity worldwide. The $\beta_{3}$-adrenergic receptor gene (ADRB3) is potentially linked to obesity, insulin resistance, diabetes, and hypertension based on its role in energy homeostasis and lipolysis in human adipose tissue. However, the relationship between $A D R B 3$ gene polymorphisms and CAD remains unclear. we sought to assess this association in the Han and Uygur populations of China.

Methods: We used the following two case-control studies: a Han population (308 CAD patients and 294 control subjects) and an Uygur population (259 CAD patients and 161 control subjects). All 1022 participants were genotyped for the two single nucleotide polymorphisms (SNPs) (rs1892818, rs9693898) of ADRB3 using real-time polymerase chain reaction (TaqMan).

Results: We found that the rs 1892818 CT genotype (8.5\% compared with $3.9 \%, P=0.019)$ and T allele (4.3\% compared with $1.9 \%, P=0.021$ ) were more frequent in control subjects than in CAD patients of the Han, but not Uygur population. No significant differences in rs 9693898 of ADRB3 were found between CAD patients and control subjects for both populations. After adjusting for other confounders, logistic regression analysis suggested that the difference remained significant between the two groups in the Han population (CT compared with CC, $P=0.036, \mathrm{OR}=0.410,95 \%$ Cl: $0.178-$ 0.944).

Conclusion: Our results suggest that $A D R B 3$ rs1892818 is associated with CAD in a Han population and that the CT genotype of $A D R B 3$ rs1892818 might be a protective factor for CAD in Han individuals.

\section{Introduction}

Coronary artery disease (CAD) is one of the major cardiovascular diseases resulting from interactions between genetics, the environment, and an unhealthy lifestyle, and it is the leading cause of death globally [1]. Advances in genome-wide association studies (GWASs) have provided insights into many different genetic factors that contribute to CAD. From such studies, more than 50 independent CAD-associated genetic loci have been found to be firmly associated with this disease, most of which reside in non-coding regions of the genome [2]. Many studies have demonstrated that different gene variations are associated with CAD. Elnaggar et al. found that there are significant differences in 584C/T polymorphisms of the endothelial lipase-encoding gene with respect to CAD and high-density lipoprotein cholesterol (HDL-C) levels. Specifically, T-allele carriers with a higher HDL-C level are protected from CAD and this allele was found to be significantly associated with a decreased risk of CAD, independent of plasma HDL-C levels [3]. Xiao et al. performed a meta-analysis and found that the leptin rs7799039 variant might affect individual susceptibility to CAD [4]. Liu et al. identified five genes (encoding signal-induced proliferation-associated 1, transcription factor 21, SMAD family member 3 , FES proto-oncogene, and platelet-derived growth factor receptor alpha) that might modulate CAD risk through human coronary artery smooth muscle cells, with all genes having relevant functional roles in vascular remodeling [5]. Furthermore, Li et al. provided additional evidence that a genetic variation in the platelet endothelial cell adhesion molecule 1-encoding gene, namely rs1867624, and hypoxia-inducible factor 1 subunit alpha gene, namely rs2057482, can modulate lipid levels in myocardial infarction patients [6].

The $\beta_{3}$ adrenergic receptor $\left(\beta_{3} A R\right)$ belongs to the $G$ protein-coupled receptor superfamily and has seven a-helix transmembrane regions that form six rings, with three each inside and outside of the cell, and comprises 402 amino acids [7]. $\beta_{3} A R$ is mainly distributed in visceral adipose tissue, with low levels also distributed in other tissues such as myocardial tissue, gallbladder, the gastrointestinal tract, and prostate [8]. It participates in a series of lipolysis and energy regulatory processes mediated by adenylate cyclase and mediates fat metabolism-related reactions, catabolizing these molecules to produce heat [9]. A single nucleotide polymorphism (SNP) of the $\beta_{3}$ adrenergic receptor gene (ADRB3), 
namely Trp64Arg, has been deeply studied. Many studies have shown that this gene is associated with risk factors of CAD such as hypertension, insulin resistance, diabetes, atherosclerosis, abnormal lipid metabolism, and obesity [10-16]. In view of the important role of ADRB3 in these diseases, we hypothesized that it is an important factor for CAD and might also be a key candidate gene underlying the onset of this disease. However, this relationship had not been previously studied. The aim of the present study was thus to assess the association between two tag SNPs, rs 1892818 and rs9693898, of ADRB3 and CAD using a case-control design with the Han and Uygur populations of China, to provide a scientific basis for CAD pathogenesis, intervention, and gene-targeted therapy.

\section{Methods}

\section{Ethics approval of study protocol}

Written informed consent was obtained from each participant after a full explanation of this study. The study protocol was conducted according to the standards of the Declaration of Helsinki, and the study was approved by the Ethics Committee of the First Affiliated Hospital of Xinjiang Medical University.

\section{Study population}

All 1022 participations were selected from Xinjiang, the northwestern part of China. From January 2016 to December 2018, 567 CAD patients were recruited from the First Affiliated Hospital of Xinjiang Medical University. This study population consisted of 308 Han patients and 259 Uygur patients with CAD. CAD patients with typical chest pain, electrocardiographic changes (new pathologic Q waves, at least $1 \mathrm{~mm}$ ST segment elevation in any two or more contiguous limb leads or a new left bundle branch block, or new persistent ST-T wave changes indicative of a non-Q wave myocardial infarction) and serum creatine kinase-MB isoenzyme (CK-MB) elevations (more than 3-fold higher than the upper reference limit) were examined by coronary angiography according to the guidelines [17]. The diagnostic criteria of CAD were defined as the presence of at least one significant coronary artery stenosis of more than $50 \%$ luminal diameter based on coronary angiography. CAD patients who had a congenital hypercoagulable status with proven disease-limiting life expectancy, malignancy, connective tissue disease, impaired renal function, or chronic inflammatory disease were excluded from the study.

The control (non-CAD) participants of 294 Han and 161 Uygur Chinese individuals were selected from the Cardiovascular Risk Survey $[18,19]$. This study comprised 14,618 subjects and is a multiple-ethnic, community-based, cross-sectional study designed to investigate the prevalence, incidence, and risk factors for cardiovascular diseases in the Han, Uygur, and Kazakh populations of Xinjiang, in the northwestern part of China. This study consisted of interviews, physical examinations, and data from blood sample analyses. These subjects did not have any of the following conditions related to CAD: a positive family history, stable and unstable angina, myocardial infarction, evidence of CAD by electrocardiography and angiography, abnormality of regional wall motion, or relevant valvular abnormalities based on echocardiography. Both CAD patients and control subjects were matched for age and sex.

\section{Data collection}

Clinical data and information about the presence of traditional CAD risk factors including essential hypertension, diabetes mellitus (DM), total cholesterol (TC), triglycerides (TG), low-density lipoprotein cholesterol (LDL-C), high-density lipoprotein cholesterol (HDL-C), smoking, drinking, height, and weight were obtained from all study participants by reviewing the patients' medical records. Essential hypertension was defined as a history of hypertension and/or average systolic blood pressure (SBP) $\geq 140 \mathrm{mmHg}$ and/or an average diastolic blood pressure (DBP) $\geq 90 \mathrm{mmHg}$ on at least two separate occasions according to medical examination and history. DM was defined as fasting plasma glucose levels $\geq 7.0 \mathrm{mmol} / \mathrm{L}(126 \mathrm{mg} / \mathrm{dL})$, glucose levels $\geq 11.1 \mathrm{mmol} / \mathrm{L}(200 \mathrm{mg} / \mathrm{dL}) 2 \mathrm{~h}$ after the administration of a $75 \mathrm{~g}$ oral glucose 
load, a history of diabetes, or patients with a history of anti-diabetic medication use. Participants were considered smokers when consuming more than five cigarettes per day or nonsmokers when they had never smoked or had stopped smoking at least 1 year before sample collection. Patients who consumed $20 \mathrm{ml}$ or more of alcohol per day in the previous 6 months were considered alcohol users. The height and weight of each individual were recorded to calculate the body mass index (BMI) and determine the risk of obesity. BMI was calculated as weight divided by height squared $\left(\mathrm{kg} / \mathrm{m}^{2}\right)$.

\section{Blood collection and DNA extraction}

Blood samples were collected from all subjects using a standard venipuncture technique with ethylene diamine tetraacetic acid (EDTA)-containing tubes and centrifuged at $4000^{\prime} \mathrm{g}$ for $5 \mathrm{~min}$ to separate the plasma for a range of biochemical assays. DNA was extracted from the peripheral vein blood leukocytes using a whole-blood genome extraction kit (Beijing Bioteke Corporation, Beijing, China). DNA samples were stored at $-80{ }^{\circ} \mathrm{C}$ for genotyping.

\section{Biochemical measurements and genotyping}

Serum and plasma collected for measurements were immediately frozen at $-80{ }^{\circ} \mathrm{C}$ until use. Plasma concentrations of TG, TC, HDL-C, and LDL-C were measured using standard methods in the Central Laboratory of the First Affiliated Hospital of Xinjiang Medical University. Using the Haploview 4.2 software and the 1000 Genomes database, we obtained two tagging SNPs (rs1892818, rs9693898) for Chinese individuals using a minor allele frequency $\geq 0.05$ and linkage disequilibrium patterns with $\mathrm{r}^{2} \geq 0.8$ as a cutoff (Figure 1). We titrated the DNA concentration at $50 \mathrm{ng} / \mathrm{mL}$. The rs1892818 and rs9693898 polymorphisms of $A D R B 3$ were detected by TaqMan single nucleotide polymorphism genotyping assays in a $7900 \mathrm{HT}$ Standard real-time polymerase chain reaction (PCR) system, according to the manufacturer's recommendations (Applied Biosystems). Primers and probes used in the TaqMan SNP Genotyping Assays (Applied Biosystems) were chosen based on information available at the ABI website (www3.appliedbiosys tems.com/AB_Home/index.htm). PCR amplification was performed in a total reaction volume of $6 \mu \mathrm{L}$ containing $3 \mu \mathrm{L}$ of TaqMan Universal Master Mix, $0.15 \mu \mathrm{L}$ probes, $1.85 \mu \mathrm{L} \mathrm{ddH2O}$, and $1 \mu \mathrm{L}$ DNA with the following amplification protocol: $95^{\circ} \mathrm{C}$ for $10 \mathrm{~min}, 40$ cycles of $95^{\circ} \mathrm{C}$ for $15 \mathrm{~s}$ and $60^{\circ} \mathrm{C}$ for $1 \mathrm{~min}$. All 96 -well plates were read using the Sequence Detection Systems (SDS) automation controller software v2.4 (ABI). The SDSv2.4 endpoint typing software package was used for automatic genotyping. The results are shown in Figure 2, and the three colors represent different genotypes. Variants in the SNP (rs1892818) of the ADRB3 gene were classified into two genotypes, namely CC and CT genotypes, whereas rs9693898 of the $A D R B 3$ gene was classified into three genotypes, AA, AG, and GG (Figure 2).

\section{Statistical analyses}

The normality of parameters was assessed by a Shapiro-Wilk test. Continuous statistics that met the normality assumption are shown as the mean and standard deviation (mean \pm SD), and differences in continuous variables between the CAD patients and control subjects were analyzed using an independent-sample t-test. As some measurement data in this study did not meet the normality assumption, they were described as medians (interquartile range) and compared with the Mann-Whitney $U$ test. The Hardy-Weinberg equilibrium was assessed by Chi-square analysis. Differences in enumeration data between CAD patients and control subjects were analyzed using the Chi-square test, as were differences in distributions of genotypes and alleles between CAD patients and control subjects. Logistic regression analyses with effect ratios (odds ratio [OR] and 95\% confidence interval [CI]) were used to assess the contribution of the major risk factors. All statistical analyses were performed using SPSS 22.0 for Windows (SPSS Institute). A two-tailed value of $p<0.05$ was considered statistically significant.

\section{Results}




\section{Characteristics of study participants}

The distribution of demographic characteristics of the study participants is shown in Table 1. Overall, a total of 567 CAD patients (mean age $57.87 \pm 9.08$ and $58.2 \%$ men) and 455 controls (mean age $56.96 \pm 8.54$ and $52.53 \%$ men) were recruited in the present study. No significant differences were observed in age, sex, BMI, TC, and LDL-C between CAD patients and control subjects. The following variables were significantly different between CAD patients and control subjects: plasma levels of TG and HDL-C and the prevalence of hypertension, diabetes, smoking, and drinking $(p<0.05$ for all). In the Han population, no significant differences were observed in age, sex, BMI, TC, and LDL-C between CAD patients and control subjects. The following variables were significantly different between CAD patients and control subjects: plasma levels of TG and HDL-C and the prevalence of hypertension, diabetes, smoking, and drinking $(p<0.05$ for all). In the Uygur population, no significant differences were observed in age, sex, BMI, TC, LDL-C, diabetes, and smoking between CAD patients and control subjects. The following variables were significantly different between CAD patients and control subjects: plasma levels of TG and HDL-C and the prevalence of hypertension and drinking $(p<0.05$ for all).

\section{$A D R B 3$ genotype and allele frequencies in the two groups}

Rs1892818 and rs9693898 were in Hardy-Weinberg equilibrium in both the case and control groups (all $\mathrm{P}>0.05$, Table 2). Table 3 shows the frequency of genotypes and alleles for the tested SNP (rs1892818) of the ADRB3 gene. Overall, the results showed that the CT genotype $(6.8 \%$ compared with $3.9 \%, p=0.036)$ and $T$ allele $(3.4 \%$ compared with $1.9 \%, p=$ 0.038) were more frequent in the control subjects than in the CAD patients. Further, we also found that the CT genotype (8.5\% compared with $3.9 \%, p=0.019)$ and $T$ allele $(4.3 \%$ compared with $1.9 \%, p=0.021$ ) were more frequent in the control subjects than in the CAD patients of the Han, but not Uygur, population. Table 4 shows the frequency of genotypes and alleles for the SNP (rs9693898) of the ADRB3 gene. The distribution of rs9693898 genotypes and alleles showed no significant difference between CAD patients and control subjects both in Han and Uygur populations. To further confirm the relationship between the frequency of the CT variant of the rs 1892818 SNP in the ADRB3 gene and CAD risk in the Han population, multiple logistic regression analyses were performed by adjusting for confounding factors such as age, sex, hypertension, diabetes, smoking, drinking, and serum levels of TG and HDL-C and the difference remained significant (CT compared with CC, $\mathrm{p}=0.036, \mathrm{OR}=0.410,95 \% \mathrm{Cl}$ : 0.178-0.944; Table 5).

\section{Discussion}

CAD is a complex disease and its etiology and pathogenesis are likely polyfactorial due to the inheritance of several susceptibility genes, as well as multiple environmental factors [20, 21].Recently, there has been an increase in the in-depth research on the role of SNPs in the pathogenesis of CAD [22]. Ultimately, studying genetic backgrounds might provide new insights to explore diagnostic and therapeutic approaches for CAD [23]. In the present study, we found that rs1892818 variations in the ADRB3 gene are associated with CAD in a Han population. This was the first study to investigate common allelic variants (rs1892818, rs9693898) in ADRB3 and its association with this disease in Chinese populations.

$\beta_{3} A R$ is an important component of the sympathetic nervous system. In cardiomyocytes, activation of endothelial nitric oxide synthase or neuronal nitric oxide synthase induced by activation of the $\beta_{3}$ receptor induces nitric oxide production and the activation of soluble guanylate cyclase, resulting in cGMP production and the activation of cGMP-dependent protein kinase $\mathrm{G}$ [24]. Previous studies have shown that $\beta 3 A R$ is present in the cardiovascular system, mainly in the myocardium and endothelium, where it has a prominent role in regulating metabolism, angiogenesis, vasodilation, and relaxation for cardiac contractility [25-28]. Thus, this receptor is of high interest especially for new potential therapeutic approaches for heart disease. ADRB3 is expressed in white and brown adipose tissues and in peripheral lymphocytes and 
is also involved in lipolysis and thermogenesis regulation [29]. The ADRB3 Trp64Arg polymorphism has been deeply studied with respect to its association with CAD by numerous researchers. As early as 1997, Higashi et al [30]. analyzed 83 Japanese patients with CAD and 107 healthy controls and found that the ADRB3 Trp64Arg variation was significantly correlated with this disease. Further, Xia et al [31]. recently studied Chinese patients with myocardial infarction, including 717 patients with myocardial infarction and 612 healthy controls, and found that the ADRB3 Trp64Arg mutation increased the risk of myocardial infarction. A possible reason for this is that when the ADRB3 gene is mutated, it might cause $\beta 3 A R$ structural and functional changes, affecting lipid metabolism and leading to an increased risk of hypertension, diabetes, and obesity [32,33]. Previously, we found that the rs2298423 polymorphism of ADRB3 in an Uygur population was correlated with serum TC and LDL-C levels, and that the G allele might be a risk factor for elevated levels of both [34]. However, the research conclusions were not consistent, as a number of studies in Germany [35], India [36], Saudi Arabia [37], and China [38] did not find a significant correlation between the ADRB3 Trp64Arg polymorphism and CAD.

Because the ADRB3 gene is polymorphic in the human beings, the rs1892818 and rs9693898 SNPs were selected in this study. We performed a case-control study to observe the relationship between genetic polymorphisms in this gene and CAD. Univariate analysis showed that the age and sex of the case and control groups were matched. Further, rs 1892818 and rs9693898 were in Hardy-Weinberg equilibrium both in the case and control groups. Variants in the rs1892818 SNP of ADRB3 were classified into two genotypes, CC and CT, whereas those of rs 9693898 were classified into three genotypes, namely AA, AG, and GG. We found that the CT genotype and T allele of rs 1892818 were more frequent in the control subjects than in the CAD patients of the Han, but not Uygur population. Further, after adjusting for some confounders, the association remained significant, which indicated that the rs1892818 CT genotype might be considered a protective factor for CAD in Han individuals. In our study, we found that the distributions of rs1892818 genotypes and alleles did not show any significant difference between CAD patients and control subjects in the Uygur population. The reason for these distinct results might be attributed to differences in ethnicity, lifestyle, diet, and sources of test samples. Considering domestic and foreign studies, there has been almost no research on these two SNPs. Therefore, additional larger-scale studies based on different populations with more detailed data on environmental exposure are required to verify these findings.

\section{Conclusion}

In brief, our study demonstrated that the ADRB3 rs1892818 polymorphism is significantly correlated with CAD, especially in Han populations. Additionally, the CT genotype of this polymorphism might be considered a protective factor for CAD in these individuals. This conclusion could be helpful to develop novel personalized CAD treatment approaches. Considering the sample size was relatively small, more research, based on large samples and multi-ethnic cohorts, on the association between ADRB3 gene polymorphisms and CAD is needed to further confirm our conclusions.

\section{Declarations}

\section{Acknowledgements}

We thank all the paticipants for their involvement in this study.

\section{Authors' contributions}

Jin-Yu Zhang and Qian Zhao contributed equally to this work. Jin-Yu Zhang and Qian Zhao performed all the experiments, analyzed all the data and prepared the manuscript, Yi-Ning Yang participated in the study design, supervised and assisted the statistical analysis and revised the manuscript. Other authors supervised the molecular genetic analysis and sample collection, assisted with input of clinical data. All the authors have read and approved the final manuscript. 


\section{Funding}

This work was supported by the National Key R\&D Program of China (NO. 2018YFC1312804) and the National Natural Science Foundation of China (No. 81460069, 81700315, and 81770363).

\section{Availability of data and materials}

The datasets during and/or analyzed during the current study available from

the corresponding author on reasonable request.

\section{Ethics approval and consent to participate}

Written informed consent was obtained from each participant after a full explanation of this study. The study protocol was conducted according to the standards of the Declaration of Helsinki, and the study was approved by the Ethics Committee of the First Affiliated Hospital of Xinjiang Medical University.

\section{Consent for publication}

All authors have read and approved the manuscript for publication.

\section{Competing interests}

The authors declare that they have no conflict of interest.

\section{Author details}

${ }^{1}$ State Key Laboratory of Pathogenesis, Prevention and Treatment of High Incidence Diseases in Central Asia, Department of Cardiology, The First Affiliated Hospital of Xinjiang Medical University, Urumqi 830054, China. ${ }^{2}$ Xinjiang Key Laboratory of Cardiovascular Disease Research, Clinical Medical Research Institute of First Affiliated Hospital of Xinjiang Medical University, Urumqi, 830054, China. ${ }^{3}$ Department of Rehabilitation, The First Affiliated Hospital of Xinjiang Medical University, Urumqi 830054, China.

\section{Abbreviations}

ADRB3:ß3-adrenergic receptor gene; BMI:body mass index; $\beta 3 A R: \beta 3$ adrenergic receptor; $C A D$ :Coronary artery disease; $C K-$ $M B: c r e a t i n e ~ k i n a s e-M B$ isoenzyme;

Cl:confidence interval; DM:diabetes mellitus; DBP:diastolic blood pressure; EDTA:ethylene diamine tetraacetic acid; GWASs:genome-wide association studies;

HDL-C:high-density lipoprotein cholesterol; LDL-C:Iow-density lipoprotein cholesterol; OR:odds ratio; PCR:polymerase chain reaction; SNP:single nucleotide polymorphism; SBP:systolic blood pressure; SDS:Sequence Detection Systems; TaqMan:real-time polymerase chain reaction; TC:total cholesterol; TG:triglycerides

\section{References}

1. Malakar AK, Choudhury D, Halder B, Paul P, Uddin A, Chakraborty S. A review on coronary artery disease, its risk factors, and therapeutics. J Cell Physiol. 2019; 1-12. 
2. Zhao X, Luan YZ, Zuo X, Chen YD, Qin J, Jin L, Tan Y, Lin M, Zhang N, Liang Y, Rao SQ. Identification of risk pathways and functional modules for coronary artery disease based on genome-wide SNP Data. Genomics Proteomics Bioinformatics. 2016;14(6):349-56.

3. Elnaggar IZ, Hussein S, Amin MI, Abdelaziz EA. Association of 584C/T polymorphism in endothelial lipase gene with risk of coronary artery disease. J Cell Biochem. 2019;1-7.

4. Xiao P, Shi J, Liu X. Associations of leptin and leptin receptor genetic variants with coronary artery disease: a metaanalysis. Biosci Rep. 2019;39(6):1-17.

5. Liu B, Pjanic M, Wang T, Nguyen T, Gloudemans M, Rao A, Castano VG, Nurnberg S, Rader DJ, Elwyn S, Ingelsson E, Montgomery SB, Miller CL, Quertermous T. Genetic Regulatory Mechanisms of Smooth Muscle Cells Map to Coronary Artery Disease Risk Loci. Am J Hum Genet. 2018;103(3):1-12.

6. Li Y, Wang S, Zhang D, Xu X, Yu B, Zhang Y. The association of functional polymorphisms in genes expressed in endothelial cells and smooth muscle cells with the myocardial infarction. Hum Genomics. 2019;13(1):1-10.

7. Yang W, Wei X, Su X, Shen Y, Jin W, Fang Y. Depletion of $\beta 3$-adrenergic receptor induces left ventricular diastolic dysfunction via potential regulation of energy metabolism and cardiac contraction. Gene. 2019;697:1-10.

8. Yoneshiro T, Shin W, Machida K, Fukano K, Tsubota A, Chen Y, Yasui H, Inanami O, Okamatsu-Ogura Y, Kimura K. Differentiation of bone Marrow- derived cells toward thermogenic adipocytes in white adipose tissue induced by the B3 adrenergic stimulation. FASEB J. 2019;33(4):5196-207.

9. Olsen JM, Csikasz RI, Dehvari N, Lu L, Sandström A, Öberg Al, Nedergaard J, Stone-Elander S, Bengtsson T. $\beta$ Adrenergically induced glucose uptake in brown adipose tissue is independent of UCP1 presence or activity: Mediation through the mTOR pathway. Mol Metab. 2017;6(6):611-9.

10. Li YY, Lu XZ, Wang H, Zhou YH, Yang XX, Geng HY, Gong G, Kim HJ.ADRB3 Gene Trp64Arg Polymorphism and Essential Hypertension: A Meta-Analysis Including 9,555 Subjects. Front Genet. 2018;9:106.

11. Rajan S, Satish S, Shankar K, Pandeti S, Varshney S, Srivastava A, Kumar D, Gupta A, Gupta S, Choudhary R, Balaramnavar VM, Narender T, Gaikwad AN. Aegeline inspired synthesis of novel $\beta 3$-AR agonist improves insulin sensitivity in vitro and in vivo models of insulin resistance. Metab Clin Exp. 2018;85:1-13.

12. Burguete-Garcia Al, Martinez-Nava GA, Valladares-Salgado A, Bermudez Morales VH, Estrada-Velasco B, Wacher N, Peralta-Romero J, Garcia-Mena J, Parra E, Cruz M. Association of $\beta 1$ and $\beta 3$ adrenergic receptors gene polymorphisms with insulin resistance and high lipid profiles related to type 2 diabetes and metabolic syndrome. Nutr Hosp. 2014;29(6):1327-34.

13. Iemitsu M, Fujie S, Murakami H, Sanada K, Kawano H, Gando Y, Kawakami R, Tanaka N, Miyachi M. Higher cardiorespiratory fitness attenuates the risk of atherosclerosis associated with ADRB3 Trp64Arg polymorphism. Eur J Appl Physiol. 2014;114(7):1421-28.

14. Daghestani M, Daghestani M, Daghistani M, Eldali A, Hassan ZK, Elamin MH, Warsy A. ADRB3 polymorphism rs4994 (Trp64Arg) associates significantly with bodyweight elevation and dyslipidaemias in Saudis but not rs1801253 (Arg389Gly) polymorphism in ARDB1. Lipids Health Dis. 2018;17(1):58.

15. De Luis Román DA, Primo D, Izaola O, Aller R. Relation of Trp64Arg polymorphism of beta 3 adrenoreceptor gene with metabolic syndrome and insulin resistance in obese women. Nutr Hosp. 2017;34(2):383-8.

16. Hong S, Song W, Zushin PH, Liu B, Jedrychowski MP, Mina Al, Deng Z, Cabarkapa D, Hall JA, Palmer CJ, Aliakbarian H, Szpyt J, Gygi SP, Tavakkoli A, Lynch L, Perrimon N, Banks AS. Phosphorylation of Beta-3 adrenergic receptor at serine 247 by ERK MAP kinase drives lipolysis in obese adipocytes. Mol Metab. 2018;12:1-13.

17. Gibbons RJ, Abrams J, Chatterjee K, Daley J, Deedwania PC, Douglas JS, Ferguson TB, Fihn SD, Fraker TD, Gardin JM, O'Rourke RA, Pasternak RC, Williams SV. ACC/AHA 2002 guideline update for the management of patients with chronic stable angina-summary article: a report of the American College of Cardiology/American Heart 
Association Task Force on practice guidelines (Committee on the Management of Patients With Chronic Stable Angina). J Am Coll Cardiol 2003;41(1):159-68.

18. Xie X, Ma YT, Yang YN, Fu ZY, Li XM, Huang D, Ma X, Chen BD, Liu F. Polymorphisms in the SAA1/2 gene are associated with carotid intima media thickness in healthy Han Chinese subjects: the Cardiovascular Risk Survey. PLoS One. 2010;5(11):e13997.

19. Pan S, Yu ZX, Ma YT, Liu F, Yang YN, Ma X, Fu ZY, Li XM, Xie X, Chen Y, Chen B, He CH. Appropriate body mass index and waist circumference cutoffs for categorization of overweight and central adiposity among Uighur adults in Xinjiang. PLoS One. 2013;8(11): e80185.

20. Roberts R, Campillo A. Genetic stratification for primary prevention of coronary artery disease. Curr Opin Cardiol. 2018;33(5):529-34.

21. Chen H, Ding S, Zhou M, Wu X, Liu X, Wu Y, Liu D. Association of rs662799 in APOA5 with CAD in Chinese Han population. BMC Cardiovasc Disord. 2018;18(1):2.

22. Zhao Y, Leman LJ, Search DJ, Garcia RA, Gordon DA, Maryanoff BE, Ghadiri MR. Self-assembling cyclic d, I-apeptides as modulators of plasma HDL function. A supramolecular approach toward antiatherosclerotic agents. ACS Cent Sci. 2017;3(6):639-46.

23. Li X, Luo JY, Zhang L, Yang YN, Xie X, Liu F, Chen BD, Ma YT. Variant of PAl-2 gene is associated with coronary artery disease and recurrent coronary event risk in Chinese Han population. Lipids Health Dis. 2015;14:148.

24. Skeberdis VA. Structure and function of beta3-adrenergic receptors. Medicina (Kaunas). 2004;40(5):407-13.

25. Dessy C, Moniotte S, Ghisdal P, Havaux X, Noirhomme P, Balligand JL. Endothelial beta3-adrenoceptors mediate vasorelaxation of human coronary microarteries through nitric oxide and endothelium-dependent hyperpolarization. Circulation. 2004;110(8):948-54.

26. Rozec B, Gauthier C. Beta3-adrenoceptors in the cardiovascular system: putative roles in human pathologies. Pharmacol Ther. 2006;111(3):652-73.

27. Simard PM, Atgié C, Mauriège P, D'Allaire F, Bukowiecki LJ. Comparison of the lipolytic effects of norepinephrine and BRL 37344 in rat brown and white adipocytes. Obes Res. 1994;2(5):424-31.

28. Dessy C, Balligand JL. Beta3-adrenergic receptors in cardiac and vascular tissues emerging concepts and therapeutic perspectives. Adv Pharmacol. 2010;59: 135-63.

29. Ryuk JA, Zhang X, Ko BS, Daily JW, Park S. Association of $\beta 3$-adrenergic receptor rs 4994 polymorphisms with the risk of type 2 diabetes: A systematic review and meta-analysis. Diabetes Res Clin Pract. 2017;129:86-96.

30. Higashi K, Ishikawa T, Ito T, Yonemura A, Shige H, Nakamura H. Association of a genetic variation in the beta 3 adrenergic receptor gene with coronary heart disease among Japanese. Biochem Biophys Res Commun. 1997;232(3):728-30.

31. Xia K, Ding R, Zhang Z, Li W, Shang X, Yang X, Wang L, Zhang Q. The association of eight potentially functional polymorphisms in five adrenergic receptor-encoding genes with myocardial infarction risk in Han Chinese.Gene. 2017;624.

32. Ishino S, Sugita T, Kondo Y, Okai M, Tsuchimori K, Watanabe M, Mori I, Hosoya M, Horiguchi T, Kamiguchi H. Glucose uptake of the muscle and adipose tissues in diabetes and obesity disease models: evaluation of insulin and $\beta 3-$ adrenergic receptor agonist effects by 18 F-FDG. Ann Nucl Med. 2017;31(5):413-23.

33. Karimi Galougahi K, Liu CC, Garcia A, Fry NA, Hamilton EJ, Figtree GA,Rasmussen HH. $\beta 3$-Adrenoceptor activation relieves oxidative inhibition of the cardiac $\mathrm{Na}+\mathrm{K}+$ pump in hyperglycemia induced by insulin receptor blockade. Am J Physiol Cell Physiol. 2015;309(5):286-95.

34. Zhang JY, Li XM, Yang YN, Ma YT, Xie X, Xiang Y, Liu F, Chen BD, Pan S,Dong XH. Distribution of $\beta 3$-adrenergic receptors gene polymorphisms and itsassociation with serum lipid in Han and Uighur populations in Xinjiang. 
ChineseJournal of Epidemiology. 2015;36(6):653-57.

35. Stangl K, Cascorbi I, Laule M, Stangl V, Vogt M, Ziemer S, Roots I, Wernecke K, Baumann G, Hauner H. Elevated serum leptin in patients with coronary artery disease: no association with the Trp64Arg polymorphism of the beta3adrenergic receptor. Int J Obes Relat Metab Disord. 2000;24(3):369-75.

36. Kumar S, Mishra A, Srivastava A, Mittal T, Garg N, Mittal B. Significant role of ADRB3 rs4994 towards the development of coronary artery disease. Coron Artery Dis 2014;25(1):29-34.

37. Abu-Amero KK, Al-Boudari OM, Mohamed GH, Dzimiri N. Beta 3 adrenergic receptor Trp64Arg polymorphism and manifestation of coronary artery disease in Arabs. Hum Biol. 2005;77(6):795-802.

38. Sheu WH, Lee WJ, Yao YE, Jeng CY, Young MM, Chen YT. Lack of association between genetic variation in the beta3adrenergic receptor gene and insulin resistance in patients with coronary heart disease. Metab Clin Exp. 1999; 48(5):651-54.

\section{Tables}

Table 1. General characteristics of study participants

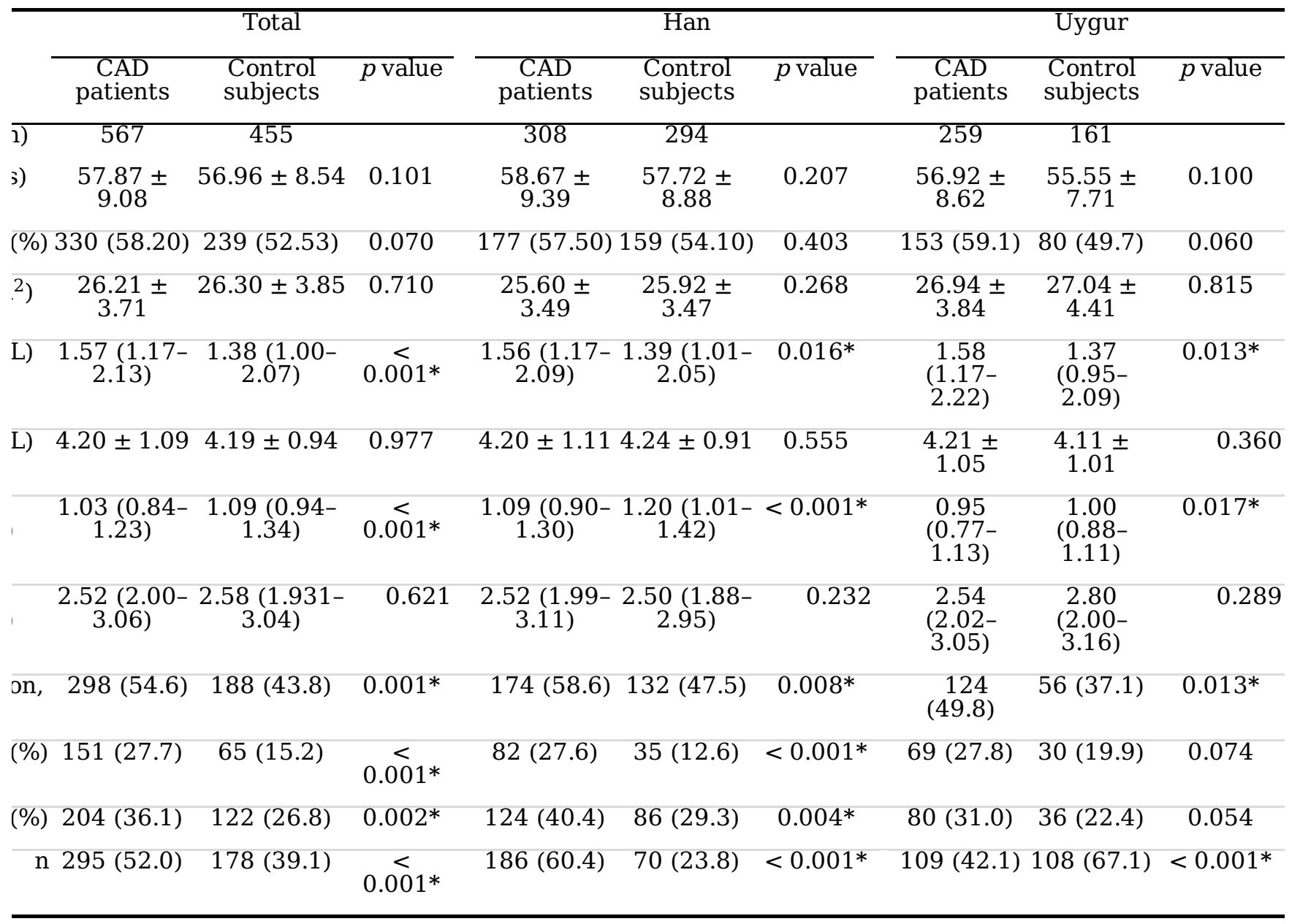

Continuous variables were expressed as the mean \pm SD and median (interquartile range). Categorical variables are expressed as numbers and percentages. The figures outside the parentheses are the numbers of cases and inside the parentheses are the percentages. * indicates significance $(p<0.05)$

CAD, coronary artery disease; BMI, body mass index; TG, triglyceride; TC, total cholesterol; HDL-C, highdensity lipoprotein cholesterol; LDL-C, low-density lipoprotein cholesterol. 
Table 2. Hardy-Weinberg equilibrium test of rs1892818 and rs9693898 genotype distribution in Han and Uygur patients with coronary artery disease.

\begin{tabular}{|c|c|c|c|c|c|c|c|c|c|}
\hline & & \multicolumn{3}{|c|}{ rs1892818 } & \multirow[t]{2}{*}{$p$ value } & \multicolumn{3}{|c|}{ rs9693898 } & \multirow[t]{2}{*}{$p$ value } \\
\hline & & $\mathrm{CC}$ & $\mathrm{CT}$ & $\mathrm{TT}$ & & AA & $\mathrm{AG}$ & GG & \\
\hline \multirow[t]{6}{*}{$\overline{\operatorname{Han}}$} & CAD patients & & & & & & & & \\
\hline & Number of experimenters & 296 & 12 & 0 & 0.727 & 228 & 73 & 7 & 0.687 \\
\hline & Number expected & 296.1 & 11.8 & 0.1 & & 227.1 & 74.7 & 6.1 & \\
\hline & Control subjects & & & & & & & & \\
\hline & Number of experimenters & 269 & 25 & 0 & 0.446 & 208 & 83 & 3 & 0.090 \\
\hline & Number expected & 269.5 & 23.9 & 0.5 & & 211.7 & 75.5 & 6.7 & \\
\hline \multirow[t]{6}{*}{ Uygur } & CAD patients & & & & & & & & \\
\hline & Number of experimenters & 249 & 10 & 0 & 0.751 & 184 & 69 & 6 & 0.875 \\
\hline & Number expected & 249.1 & 9.8 & 0.1 & & 184.3 & 68.3 & 6.3 & \\
\hline & Control subjects & & & & & & & & \\
\hline & Number of experimenters & 155 & 6 & 0 & 0.810 & 116 & 41 & 4 & 0.868 \\
\hline & Number expected & 155.1 & 5.9 & 0.1 & & 115.7 & 41.5 & 3.7 & \\
\hline
\end{tabular}

CAD, coronary artery disease.

Table 3. Association analyses between genotypes and rs1892818 polymorphism alleles in control subjects and patients with coronary artery disease

\begin{tabular}{|c|c|c|c|c|c|c|c|c|c|c|c|}
\hline \multirow{2}{*}{\multicolumn{3}{|c|}{$\begin{array}{c}\text { SNP } \\
\text { Polymorphisms }\end{array}$}} & \multicolumn{3}{|c|}{ Total } & \multicolumn{3}{|c|}{ Han } & \multicolumn{3}{|c|}{ Uygur } \\
\hline & & & CAD & Control & $p$ value & CAD & Control & $p$ value & CAD & Control & $p$ value \\
\hline \multirow[t]{5}{*}{$\overline{\text { Rs1892818 }}$} & \multicolumn{2}{|c|}{ GenotypeCC } & $\begin{array}{c}545 \\
(96.1)\end{array}$ & $\begin{array}{c}424 \\
(93.2)\end{array}$ & $0.036^{*}$ & $\begin{array}{c}296 \\
(96.1)\end{array}$ & $\begin{array}{c}269 \\
(91.5)\end{array}$ & \multirow[t]{3}{*}{$0.019^{*}$} & $\begin{array}{c}249 \\
(96.1)\end{array}$ & $\begin{array}{c}155 \\
(96.3)\end{array}$ & \multirow[t]{3}{*}{0.944} \\
\hline & \multirow{4}{*}{$\begin{array}{l}\text { Allele } \\
\text { n (\%) }\end{array}$} & CT & $22(3.9)$ & 31 (6.8) & & $12(3.9)$ & 25 (8.5) & & $\begin{array}{c}10 \\
(3.9)\end{array}$ & $6(3.7)$ & \\
\hline & & $\mathrm{TT}$ & $0(0)$ & $0(0)$ & & $0(0)$ & $0(0)$ & & $0(0)$ & $0(0)$ & \\
\hline & & $\mathrm{C}$ & $\begin{array}{l}1112 \\
(98.1)\end{array}$ & $\begin{array}{c}879 \\
(96.6)\end{array}$ & 0.038* & $\begin{array}{c}604 \\
(98.1)\end{array}$ & $\begin{array}{c}563 \\
(95.7)\end{array}$ & $0.021 *$ & $\begin{array}{c}508 \\
(98.1)\end{array}$ & $\begin{array}{c}316 \\
(98.1)\end{array}$ & \multirow[t]{2}{*}{0.945} \\
\hline & & $\mathrm{T}$ & $22(1.9)$ & $31(3.4)$ & & $12(1.9)$ & $25(4.3)$ & & $\begin{array}{l}10 \\
(1.9)\end{array}$ & $6(1.9)$ & \\
\hline
\end{tabular}

* indicates significance $(p<0.05)$. CAD, coronary artery disease.

Table 4. Association analyses between genotypes and rs9693898 polymorphism alleles in control subjects and patients with coronary artery disease

CAD, coronary artery disease. 


\begin{tabular}{|c|c|c|c|c|c|c|c|c|c|c|c|}
\hline \multirow[t]{2}{*}{ SNP } & \multicolumn{2}{|c|}{ Polymorphisms } & \multicolumn{4}{|c|}{ Total } & \multicolumn{2}{|c|}{ Han } & \multicolumn{3}{|c|}{ Uygur } \\
\hline & & & CAD & \multicolumn{2}{|c|}{ Control $P$ value } & \multicolumn{3}{|c|}{ CAD Control $P$ value } & \multicolumn{3}{|c|}{ CAD Control $p$ value } \\
\hline \multirow[t]{5}{*}{$\overline{R s 9693898}$} & \multicolumn{2}{|c|}{ Genotype AA } & $412(72.7)$ & $\begin{array}{c}324 \\
(71.2)\end{array}$ & 0.527 & $\begin{array}{l}228 \\
(74)\end{array}$ & $\begin{array}{c}208 \\
(70.8)\end{array}$ & 0.242 & $\begin{array}{c}184 \\
(71.1)\end{array}$ & $\begin{array}{l}116 \\
(72)\end{array}$ & 0.962 \\
\hline & & AG & $142(25.0)$ & $\begin{array}{c}124 \\
(27.3)\end{array}$ & & $\begin{array}{c}73 \\
(23.7)\end{array}$ & $\begin{array}{c}83 \\
(28.2)\end{array}$ & & $\begin{array}{c}69 \\
(26.6)\end{array}$ & $\begin{array}{c}41 \\
(25.5)\end{array}$ & \\
\hline & & GG & $13(2.3)$ & $7(1.5)$ & & $\begin{array}{c}7 \\
(2.3)\end{array}$ & $3(1.0)$ & & $\begin{array}{c}6 \\
(2.3)\end{array}$ & $4(2.5)$ & \\
\hline & \multirow{2}{*}{$\begin{array}{l}\text { Allele } \\
\text { n (\%) }\end{array}$} & A & $966(85.2)$ & $\begin{array}{c}772 \\
(84.8)\end{array}$ & 0.826 & $\begin{array}{c}529 \\
(85.8)\end{array}$ & $\begin{array}{c}499 \\
(84.8)\end{array}$ & 0.619 & $\begin{array}{c}437 \\
(84.4)\end{array}$ & $\begin{array}{c}273 \\
(84.8)\end{array}$ & 0.870 \\
\hline & & G & $168(14.8)$ & $\begin{array}{c}138 \\
(15.2)\end{array}$ & & $\begin{array}{c}87 \\
(14.2)\end{array}$ & $\begin{array}{c}89 \\
(15.2)\end{array}$ & & $\begin{array}{c}81 \\
(15.6)\end{array}$ & $\begin{array}{c}49 \\
(15.2)\end{array}$ & \\
\hline
\end{tabular}

Table 5. Multiple logistic regression analysis of coronary artery disease patients and control subjects in the Han population

\begin{tabular}{cccc}
\hline Risk factor & OR & $95 \%$ CI & $p$ value \\
\hline Genotype & 0.410 & $0.178-0.944$ & $0.036^{*}$ \\
(CT vs. CC) & & \\
drinking & 5.050 & $3.471-7.349$ & $<0.001^{*}$ \\
diabetes & 2.296 & $1.433-3.678$ & $0.001^{*}$ \\
constant & 1.191 & $0.484-2.933$ & 0.703 \\
& & & \\
\hline
\end{tabular}

* indicates significance $(p<0.05)$. CI, confidence interval; OR, odds ratio

\section{Figures}




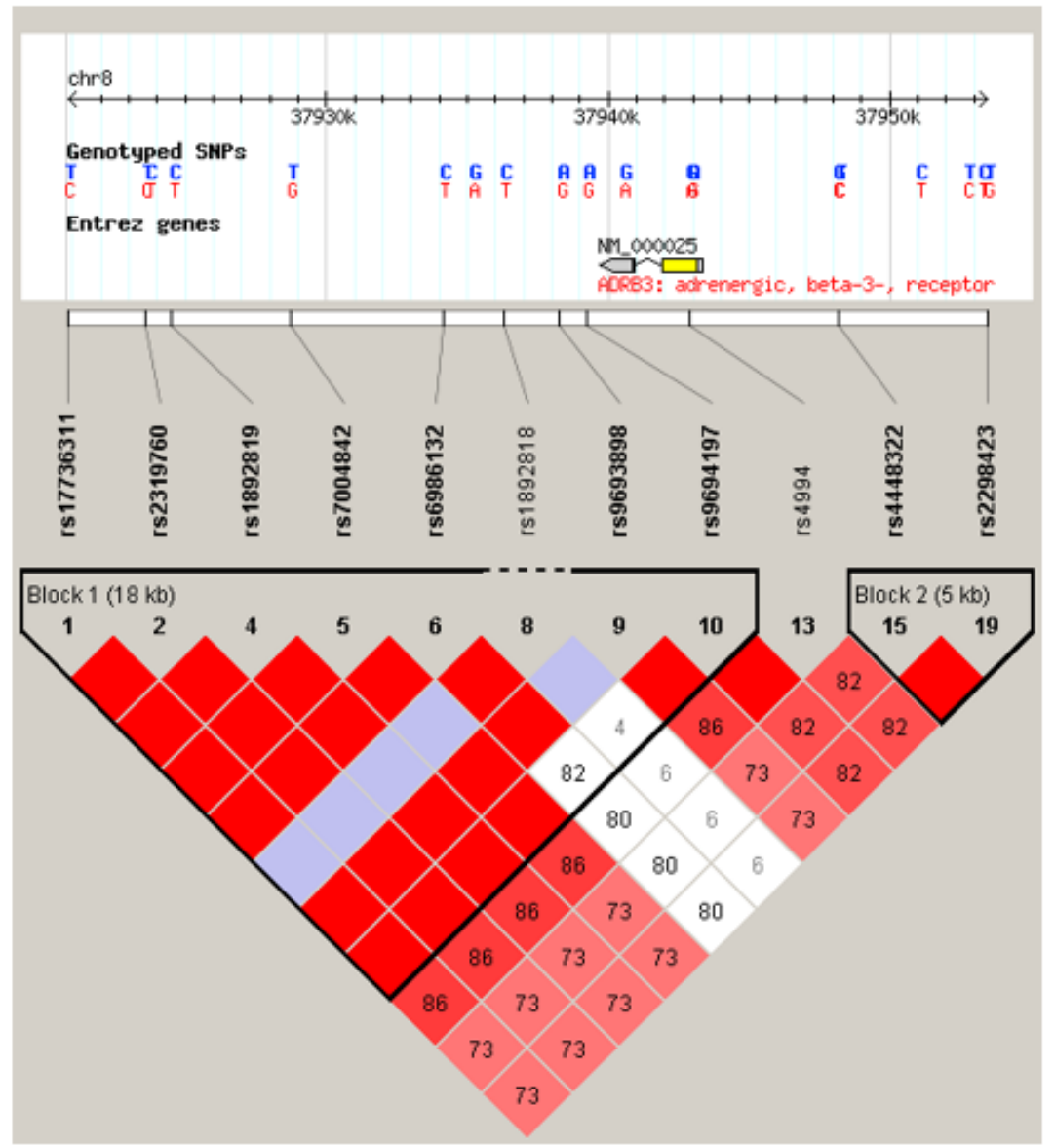

Figure 1

Selection of ADRB3 gene tag SNPs (rs1892818, rs9693898) by Haploview 4.2 

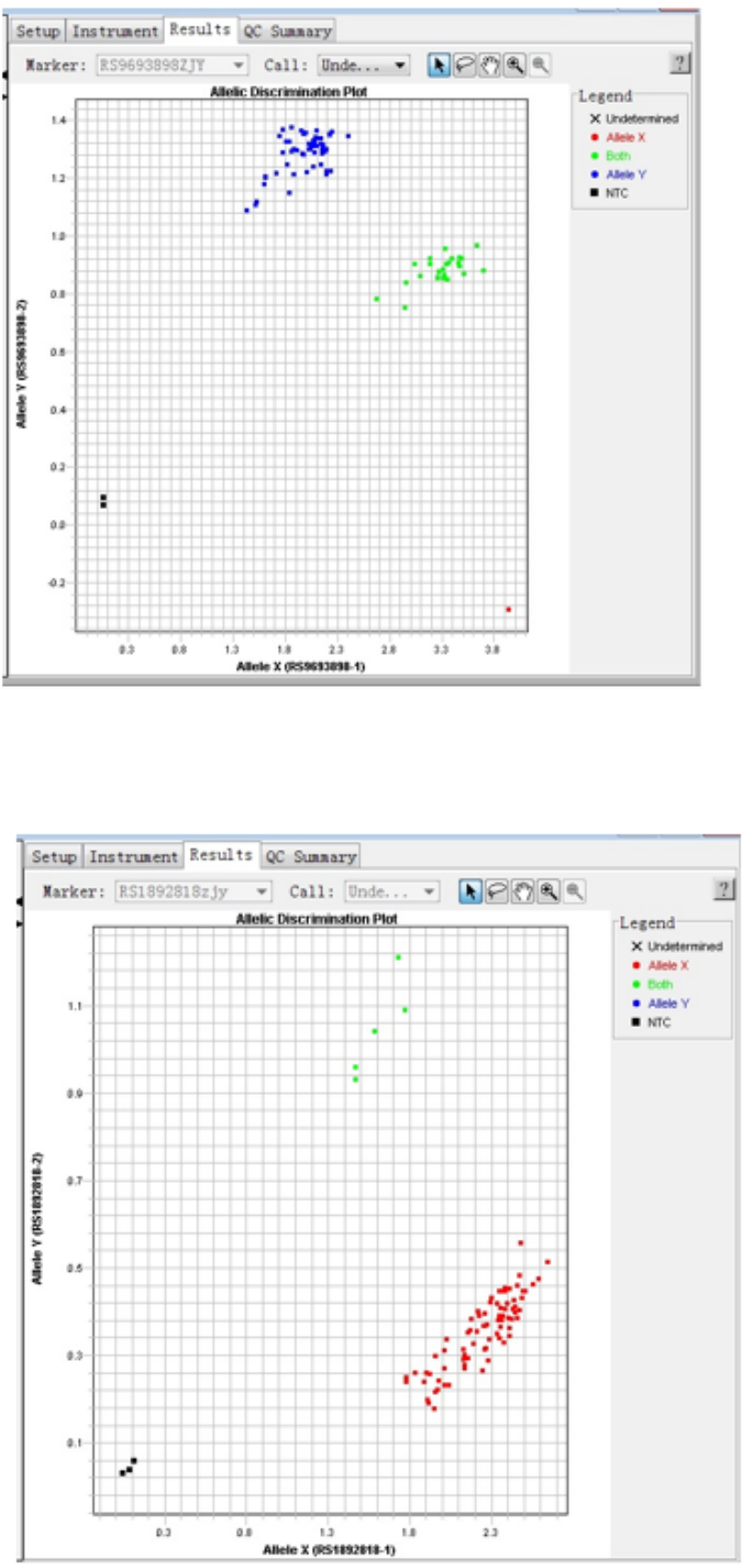

Figure 2

Schematic diagram of Taqman genotyping results. 